\title{
Tecnologias digitais na formação e prática dos futuros professores de Matemática
}

Marco Aurélio Kalinke $\frac{\text { kalinke@utfpr.edu.br }}{0000-0002-5484-1724}$ Universidade Tecnológica Federal do Paraná, Curitiba, Paraná, Brasil.

\section{Luciane Ferreira Mocrosky} mocrosky@utfpr.edu.br

Universidade Tecnológica Federal do Paraná, Curitiba, Paraná, Brasil

\section{Maria Lúcia Panossian} mlpanossian@utfpr.edu.br 000-0001-5847-4485 Universidade Tecnológica Federal do Paraná, Curitiba, Paraná, Brasil.

Edna Sakon Banin ednas@utfpr.edu.br Universidade Tecnológica Federal do Paraná, Curitiba, Paraná, Brasil

\begin{abstract}
RESUMO
Os modelos dos atuais cursos de formação de professores de Matemática preveem ações que busquem aproximar os futuros professores das suas práticas profissionais ao longo de toda a sua formação. Isso exige posturas inovadoras dos docentes destes cursos, de modo a buscar, ao longo das disciplinas da graduação, que os licenciandos conheçam novas possibilidades e práticas que possam ser implementadas quando formados. O texto apresenta uma discussão sobre este modelo de formação e de como a busca por esta aproximação foi desenvolvida numa disciplina em particular, cujo conteúdo estava relacionado à inserção de recursos tecnológicos no ensino da Matemática. São apresentadas as formas de trabalho da disciplina, os referencias teóricos adotados e, entre os resultados, entendeu-se que o uso diferenciado de tecnologias digitais pode incentivar nos futuros professores posturas e possibilidades inovadoras, e que o uso articulado de recursos tecnológicos possibilitou a inclusão da linguagem digital interativa em atividades matemáticas.
\end{abstract}

PALAVRAS-CHAVE: Educação Matemática. Tecnologias. Objetos de aprendizagem. 


\section{Uma compreensão inicial sobre Licenciaturas em Matemática}

Discutir formação de professores tem feito parte da rotina de acadêmicos, pesquisadores, professores e gestores educacionais, tanto em instituições públicas quanto privadas. A formação de professores de Matemática ocupa, neste cenário, lugar de destaque, mas esta posição não pode ser entendida como privilégio ou reconhecimento de uma eventual "força" das pesquisas da área. Ela surge do desconforto evidente que existe em muitos dos envolvidos com os cursos de Licenciatura em Matemática. A docência neste curso nos permite afirmar que uma parcela considerável de professores e alunos não estão satisfeitos com as práticas existentes, com a estruturação curricular e com algumas compreensões daqueles envolvidos com a formação dos futuros professores de Matemática.

As discussões se dão mesmo que a legislação procure privilegiar atividades práticas, ligadas ao ensino e à atuação docente, ampliando a carga horária de estágios supervisionados, incluindo em diversas disciplinas atividades práticas como componentes curriculares (APCC) e incentivando programas como o Programa Institucional de Bolsas de Iniciação à Docência (PIBID). Com todas as inciativas anunciadas ainda se observa uma forte presença, nas licenciaturas, de práticas que defendem que para ser um bom professor de Matemática basta saber Matemática. Fundamentados nesta crença, muitos professores exigem de seus alunos conceitos e aprofundamentos que muitas vezes não são consoantes ao perfil profissional proclamado no projeto que visa formar professores de Matemática para educação básica.

É importante destacar que há, entre os diversos modelos de cursos de Licenciatura em Matemática, aqueles que se propõe a formar profissionais para atuações específicas e aqueles que procuram ser mais abrangentes. $\mathrm{O}$ curso em tela, no conjunto da obra aqui apresentada, a Licenciatura em Matemática da UTFPR - câmpus Curitiba, propõe-se a:

\footnotetext{
Formar profissionais para atuarem no ensino da Matemática na Educação Básica (Ensino Fundamental e Ensino Médio): com sólida formação científica na área específica; sólida formação pedagógica, humana e cultural; com autonomia para formação continuada, capaz de intervir na realidade de seu entorno social em busca da consolidação da cidadania. ${ }^{1}$
}

Salta aos olhos a proposta de formar profissionais para os ensinos fundamental e médio. É com este foco, e para este modelo de licenciatura, que o texto aqui apresentado se destina.

É comum encontrar nestas licenciaturas alunos, em final de curso, que dominam técnicas de integração, resolução de equações diferenciais, teoria de grupos, corpos e anéis, mas que não sabem demonstrar a fórmula que permite resolver equações polinomiais do segundo grau, que no Brasil é comumente chamada de fórmula de Bhaskara. Muitos destes alunos também acreditam que $\sqrt{9}= \pm 3$, ignorando a associação ao módulo e, como consequência, o resultado 3 , e desconhecem que 0/0 é uma indeterminação matemática, apontando "zero" ou "não existe" como resposta, entre tantas outras situações semelhantes e não

Página | $361 \quad{ }^{1}$ http://www.utfpr.edu.br/curitiba/estruturauniversitaria/diretorias/dirgrad/departamentos/matematica/licenciatura/pagina-inicial 
menos importantes. Existe uma preocupação exacerbada com conteúdos relacionados à matemática superior e deixa-se em segundo plano a matemática "elementar", que é, em última análise, aquela que os futuros professores irão utilizar nas salas de aula da educação básica. Tem-se a impressão de que, contraditoriamente ao desenvolvimento histórico da Matemática, desconsiderase quase dez mil anos da sua evolução para atentar-se aos últimos cento e cinquenta anos do seu desenvolvimento, nos quais ela se tornou formalizada e academicamente sistematizada, tal como a conhecemos hoje.

O que se defende não é a exclusão, facilitação ou troca de disciplinas de Matemática por outras do campo da Educação, Educação Matemática, Didática ou afins. Pretende-se levantar discussões sobre que tipo de profissional está sendo formado. Que conteúdos matemáticos ele está dominando? Que Matemática lhes está sendo ensinada? Estes futuros professores estão sendo preparados para exercer a profissão de professores de Matemática de ensino básico ou estão sendo preparados para serem matemáticos, que porventura tentem ensinar Matemática?

Aqueles que não concordam com esta abordagem podem alegar que entre os alunos das licenciaturas também há aqueles que desejarão trabalhar no ensino superior, logo, precisam dominar estes conteúdos. Partindo-se desta premissa, tem-se algumas opções a seguir. Primeira delas: se faz necessária a mudança dos cursos de licenciatura como os aqui discutidos, pois seu objetivo é preparar professores para a educação básica. Se a opção for também preparar professores para o ensino superior isso precisa estar evidenciado nos documentos do curso, em particular no seu projeto pedagógico. De forma geral, não é o que se observa. Em muitos casos há uma clara disjunção entre o proposto nos documentos e o praticado nas salas de aula das universidades brasileiras. Segunda opção: eliminase a necessidade de mestrado e doutorado para ingresso na carreira docente do ensino superior, uma vez que, nesta abordagem dissonante, o aluno será formado para ser professor de Matemática em qualquer nível após cursar a licenciatura. Assim, não faz sentido que ele seja preparado por mais, no mínimo seis anos (dois de mestrado e quatro de doutorado), para ser um professor do ensino superior. Aqui não será discutida a formação de pesquisadores, que é, em última análise, a função dos cursos de pós-graduação stricto sensu. $O$ foco são as exigências legais para que se ocupe o cargo de docente de ensino superior nas universidades públicas brasileiras.

Defende-se, então, que a formação de professores de Matemática para a educação básica seja repensada, direcionando esforços para preparar melhor os profissionais que irão atuar neste nível de ensino, sem que isso signifique "facilitar o curso" ou "aprovar todos os alunos", que são argumentos comuns entre os que não concordam com propostas como as aqui apresentadas. $O$ que se defende é a valorização dos aspectos e conteúdos relacionados à futura profissão, em detrimento a outros com as quais os futuros profissionais dificilmente irão se deparar novamente. Enquanto professores de educação básica, a sua formação necessita ser direcionada para tal, aprofundando aspectos e abrindo possibilidades de enfrentamento das complexidades da profissão professor, comumente deixados em segundo plano pelas licenciaturas no modelo atualmente praticado nas universidades brasileiras.

Num modelo que privilegie a formação de professores e não de matemáticos, assume-se que a prática deva estar intimamente ligada à teoria. É importante que 
os futuros professores possam atuar em realidades próximas àquelas que irão encontrar depois de formados. Isso se consegue com a valorização dos espaços de estágios supervisionados, em ações de monitoria, atividades em laboratório de Matemática, programas como o PIBID e, sempre que possível, dentro das próprias disciplinas do curso.

A inclusão de atividades relacionadas ao exercício do magistério nas disciplinas nem sempre é uma tarefa simples. Há, inclusive, estratégias legais pensadas para tornar esta inclusão mais efetiva, entre as quais se destacam as APCC (MOCROSKY, KALINKE, ESTEPHAN, 2012). Com a intenção de colaborar nesta discussão, algumas possibilidades de atividades direcionadas para a formação do professor de educação básica serão apresentadas, em particular aquelas desenvolvidas com uso de Tecnologias Digitais (TD).

\section{Tecnologias no ensino da Matemática: um caminho percorrido em uma unidade curricular}

A proposta deste texto é apresentar como foi trabalhada, ao longo de oito semestres, a disciplina Tecnologias no Ensino da Matemática, presente no terceiro período letivo do curso de Licenciatura em Matemática da UTFPR, Câmpus Curitiba, de forma a colaborar na formação dos futuros professores para as diferentes realidades profissionais que irão encontrar quando formados.

A disciplina tem sua carga horária total de 54 horas aula ( 3 aulas semanais), totalizada em 34 aulas teóricas, somadas com 3 horas aula para atividades práticas supervisionadas (APS) e 17 horas aula para APCC. Esta disciplina foi ofertada pela primeira vez no primeiro semestre letivo de 2012 e tem ofertas contínuas, desde então, a cada novo semestre letivo. O seu objetivo é "estudar as tecnologias da informação e da comunicação aplicadas à Educação Matemática, como possibilidade de orientação da postura didática e investigativa do professor de Matemática." ${ }^{2}$ A dinâmica adotada nas aulas busca uma relação de diálogo entre os licenciandos, o professor e as tecnologias digitais. Para tanto, os encontros acontecem em salas de aula tradicionais e no laboratório de informática, buscando sempre a articulação teoria-prática. Nas aulas teóricas há atividades individuais e em grupo, discussões de textos e aulas expositivas. Nas aulas práticas acontece a exploração de softwares educacionais, softwares livres, sites de Matemática e educacionais, Objetos de Aprendizagem (OA) e da Lousa Digital (LD), por exemplo. O laboratório de informática em que acontecem as atividades práticas possui uma Lousa do modelo Interwrite DualBoard ${ }^{3}$ e vinte e cinco computadores.

Assume-se que a dinâmica de evolução das TD traz aos pesquisadores da área a necessidade de permanente atenção, uma vez que novas possibilidades e tecnologias surgem frequentemente e, com elas, além das necessárias atualizações pedagógicas, a pressão social, econômica e comercial para que sejam

${ }^{2}$ http://www.utfpr.edu.br/curitiba/estrutura-

universitaria/diretorias/dirgrad/departamentos/matematica/licenciatura/matriz-curricular/planos-

Págeppsins63/3 periodo/MA73F S83-Tecnologias\%20no\%20Ensino\%20de\%20Matematica.pdf

${ }^{3}$ Para mais informação, acessar: http://www.tes.com.br/detalhe/59/lousa-interativa-interwrite-dualboard 
incorporadas em processos escolares. Entende-se como fundamental que o uso de tecnologias em atividades de ensino de Matemática esteja fortemente apoiado num suporte teórico que lhes dê sustentação e ofereça aos futuros professores condições de compreender os mecanismos, sejam técnicos, cognitivos ou de assimilação, envolvidos neste uso. Para suprir esta necessidade, na disciplina em questão o embasamento adotado utiliza autores como Lévy (1993; 1999), Tikhomirov (1981) e Borba e Vilarreal (2005).

Lévy (1993; 1999) trata das relações entre tecnologia e sociedade. Entendendo a oralidade e a escrita como tecnologias, este autor defende que a sociedade é influenciada pelas tecnologias do seu tempo e que a transmissão de conhecimento está intimamente ligada às tecnologias disponíveis em cada época. Ele também apresenta as ideias de ciberespaço e cibercultura. A primeira está relacionada à reunião de todos os dados e informações presentes nos computadores e dispositivos informatizados, e como isso pode impactar nos processos sociais, entre os quais se encontram os educacionais. A cibercultura, por sua vez, trata de analisar o comportamento social frente às novidades tecnológicas e as possibilidades que ela apresenta. Para Lévy (1999) a cibercultura é um movimento que oferece novas formas de comunicação que, por sua vez, podem levar a novas formas de trocas de informações e conhecimentos, originando novas possibilidades culturais.

Tikhomirov (1981) defende que o uso de computadores leva a uma reorganização da atividade intelectual, mnemônica, comunicativa e criativa humana. Após criticar a compreensão do computador como um substituto ou complemento do homem, Tikhomirov, usando as ideias de Vygotsky, indica que o computador causa no indivíduo uma reorganização intelectual que guarda semelhanças com aquela originada pelo domínio da fala e da linguagem.

Destaque-se que estes dois autores analisam o impacto da inserção das novas tecnologias na sociedade (o primeiro) e no indivíduo (o segundo). Eles não aprofundam, contudo, aspectos relativos a esta inserção nos processos educacionais, ainda que abordem en passant a questão.

Quem aprofunda esta discussão são Borba e Villarreal (2005) que apresentam a noção de seres-humanos-com-mídias... como sendo adequada para mostrar de que forma o pensamento se reorganiza com a presença das tecnologias e que tipos de problemas são gerados por coletivos que incluem seres humanos e mídias, sejam elas lápis, papel ou as diversas facetas das tecnologias digitais. Para estes autores o pensamento matemático se modifica frente às mídias utilizadas, abrindo uma gama interessante de aplicações para novas tecnologias em atividades educacionais. Elas podem, por exemplo, justificar o uso de tecnologias para explicações de determinados assuntos àqueles alunos que não os compreenderam em exposições teóricas, tão comuns nas salas de aula atuais. Também podem ser usadas para fundamentar a inserção das TD em aulas de Matemática como disparadores de novas formas de pensar e abordar problemas matemáticos, entre outras possibilidades.

Diante do exposto, a disciplina Tecnologias no Ensino da Matemática tem procurado embasar suas atividades na junção destes autores que apresentam, respectivamente, uma fundamentação consistente sobre o uso de tecnologias e seu impacto na sociedade, no indivíduo e nos processos educacionais. Esta posição teórica é relevante, uma vez que se parte do pressuposto que sem uma 
fundamentação teórica consistente corre-se um risco grande de cair-se no campo dos "achismos" e do senso comum, incompatíveis por natureza com a proposta de fazer ciência e com o espírito de discussão acadêmica que deve se fazer presente numa universidade.

Contudo, é importante tomar cuidados para que não se recaia na armadilha de focar uma disciplina como esta exclusivamente em discussões teóricas. Entende-se que a formação de futuros professores precisa contemplar uma fundamentação teórica que enlace práticas formativas para a docência de modo que procurem aproximá-los da realidade a ser encontrada na futura rotina profissional. Assim, optou-se por não trabalhar, nesta disciplina, sobre como manusear softwares, sites ou aplicativos específicos. A opção feita foi a de discutir aspectos relacionados à sua integração em atividades de ensino de Matemática, fornecendo aos futuros professores uma base teórica de conhecimentos sobre o porquê utilizar a tecnologia, quando utilizá-la como um diferencial, quais as implicações desta utilização, e outros tópicos de igual relevância, mesclando atividades teóricas com práticas.

Nas atividades práticas os futuros professores estão em contato permanente com aspectos da sua profissão, seja pela análise e seleção de recursos didáticos, seja pela avaliação, tanto pelo docente quanto pelos seus pares, das apresentações realizadas, nas quais são avaliados, além da fluência tecnológica, diç̧ão, movimentação e demais aspectos relacionados à postura do futuro docente quando em sala de aula.

\section{Algumas TD utilizadas}

Entre as TD disponíveis, o laboratório utilizado possui uma LD instalada e o acesso a ela é liberado aos alunos, para que a conheçam e explorem. Como uma quantidade significativa de alunos tem alguma participação em programas na Universidade, tais como PIBID, monitoria ou estágio remunerado, não é raro ver pequenos grupos de alunos explorando, no contra turno, a LD e seus recursos, tal como relatado em Kalinke e Janegitz (2014).

A lousa digital possui, basicamente, as funções de um computador, acrescido de alguns recursos próprios, tais como um acervo de imagens, com mapas, figuras do corpo humano, animais, plantas, formas geométricas, entre outros. Ela possui, ainda, recursos específicos que ampliam as possibilidades para atividades interativas, aumentando a gama de ações que privilegiem a interação e a interatividade (JANEGITZ, 2014) ${ }^{4}$. A lousa digital pode ser um complemento para outros recursos que os professores usam em sala de aula, tais como vídeos e slides, por exemplo. Ela pode potencializar a construção do conhecimento a partir de atividades de cooperação e colaboração, e também permite trazer a linguagem audiovisual interativa para a sala de aula, o que amplia a possibilidade de comunicação entre os alunos e professores, tal como proposto por Nakashima e Amaral (2006).

Página | 365 4Assume-se que a interação se dá entre dois ou mais humanos, enquanto a interatividade se dá entre humanos e tecnologias, particularmente as digitais. 
Especificamente em atividades matemáticas, Derossi (2015) indica que as construções matemáticas feitas pelos alunos nas lousas digitais apresentam características distintas daquelas realizadas com lápis e papel. Para Ribeiro (2015) a LD pode ser uma aliada do professor de Matemática nos processos educacionais, desde que sua utilização esteja apoiada e planejada cuidadosamente, para que os recursos sejam explorados de diversas formas, possibilitando novas abordagens para os conteúdos matemáticos a serem trabalhados em sala de aula.

Estes recursos e diferenciais são melhor explorados, entretanto, quando nas LD são utilizados os objetos de aprendizagem. A presença dos OA é relativamente recente no cenário educacional e as suas definições são bastante amplas. A definição utilizada na disciplina é aquela apresentada em Kalinke e Mocrosky (2014, p. 62), para quem OA é "qualquer recurso virtual multimídia, que pode ser usado e reutilizado com o intuito de dar suporte à aprendizagem de um conteúdo específico, por meio de atividade interativa, apresentada na forma de animação ou simulação".

O Governo Federal desenvolveu repositórios de OA com o objetivo de incentivar o seu uso em atividades educacionais. Tratam-se de sites que servem para armazenar e disponibilizar $\mathrm{OA}$ aos usuários em geral. Entre eles estão o RIVED $^{5}$ e o BIOE $^{6}$. Governos estaduais também têm procurado incentivar esta prática. Os OA disponibilizados nestes repositórios normalmente foram desenvolvidos para serem utilizados com o uso de computadores tradicionais e não são específicos para as $L D$, o que não os impede de serem nelas utilizados. Quando utilizados em computadores eles podem gerar bons resultados que, entretanto, podem ser ampliados quando do seu uso nas LD. Isso se justifica uma vez que elas permitem ampliar as potencialidades de interatividade dos OA. O uso conjunto dos OA nas LD maximiza as características de interatividade entre os usuários e os $\mathrm{OA}$, e da interação entre dois ou mais usuários, aproveitando o melhor de cada um dos recursos (KALINKE e MOCROSKY, 2014).

Defende-se ser importante que o futuro professor aprenda a utilizar, desenvolver ou escolher os $\mathrm{OA}$ em função dos objetivos que pretende atingir e de sua própria concepção de conhecimento e de aprendizagem, distinguindo os que se prestam a um trabalho dirigido para testar conhecimentos daqueles que procuram levar o aluno a uma efetiva interatividade com o aplicativo, de forma a construir seu conhecimento, por exemplo.

Com as ferramentas das LD e os OA o professor poderá construir outros tipos de atividades, que também podem estar presentes e ser importantes para introduzir novas formas de trabalho no contexto escolar das aulas de Matemática.

Página | $366 \quad{ }^{5}$ Rede Interativa Virtual de Educação - http://rived.mec.gov.br/

${ }^{6}$ Banco Internacional de Objetos Educacionais - http://objetoseducacionais2.mec.gov.br/ 
Esse tipo de Objeto pode possibilitar ao aluno testar diferentes caminhos, acompanhar a evolução temporal das relações, verificar causa e efeito, criar e comprovar hipóteses, relacionar conceitos, despertar a curiosidade e resolver problemas, de forma atrativa e divertida, como uma brincadeira ou jogo. O OVA7 oferece oportunidades de exploração, navegação, descobertas estimulando a autonomia nas ações e nas escolhas do aluno (GALLO e PINTO, 2010, p. 4).

Aceitando os recursos interativos como os principais diferenciais da LD, os usos possíveis de serem nelas implementados serão aqui separados em três grupos: apresentação interativa; exploração de atividades interativas; criação de atividades interativas.

Na apresentação interativa, a LD é utilizada para a projeção de documentos nos mais diversos formatos, tais como pdf, doc, ppt, vídeos e outros. Neste caso, a LD se diferencia das projeções em telas comuns por permitir que o usuário interaja com o documento, destacando partes, escrevendo comentários, inserindo imagens, textos, gráficos ou outros recursos. A LD permite que estas alterações sejam gravadas, como imagens, num novo documento, ou que elas sejam descartadas e o documento inicial seja preservado, o que pode ser bastante útil para os professores que ministrem o mesmo conteúdo para várias turmas. Mantendo o documento inicial íntegro, eles podem reutilizá-lo tantas vezes quantas considerem necessário ou adequado, sem a necessidade de precisar reorganizá-lo depois de cada apresentação. De forma similar, se alguma das modificações realizadas for útil ou necessária de ser inserida no documento original, isso pode ser conseguido com a gravação das telas modificadas. 0 principal benefício deste modo de utilização é a inserção da linguagem digital interativa na sala de aula, tal como proposto por Nakashima e Amaral (2006). Ainda que este uso seja um diferencial da LD em relação a outras telas de projeção, não explora as possibilidades da LD em sua totalidade, pois ela continua sendo uma superfície de projeção, acrescida de alguns recursos novos.

Outra forma possível de utilização da LD se dá quando acontece a exploração de atividades interativas. Neste uso os recursos de interação e interatividade da LD podem ser explorados com mais profundidade. Pelas características próprias dos $\mathrm{OA}$, de serem objetos que trabalham com simulação e animação, quando se privilegia a interação e a interatividade se potencializam tanto os recursos dos objetos quanto das LD. Neste uso podem ser exploradas as ferramentas descritas anteriormente, tais como inserir comentários, imagens e outros elementos e salvar as alterações, caso isso seja necessário, bem como usar recursos da LD como os holofotes, a cortina e os instrumentos geométricos para interagir com os OA. Ele apresenta o diferencial, contudo, de agregar às ferramentas da lousa elementos que possuem atividades de animação e simulação que já foram desenvolvidos, testados, organizados e catalogados para serem utilizados em atividades matemáticas. Como casamento destas possibilidades se pode desenvolver aulas inovadoras e apresentações diferenciadas, que tem nas TD o seu suporte.

Página | 367 70VA = Objeto Virtual de Aprendizagem. É uma nomenclatura utilizada pelos autores para o que neste trabalho se chama de OA 
Há que se destacar, contudo, que neste uso o professor trabalha com atividades desenvolvidas por outros profissionais, cuja utilização nem sempre se adequa à sua realidade. É possível que atividades ou propostas que foram bemsucedidas em algumas turmas ou realidades não o sejam em outras. Cabe ao professor, que em última análise é quem melhor conhece suas turmas e as particularidades dos seus alunos, elaborar atividades que atendam a estas especificidades e que sejam pensadas para este público.

A terceira forma de compreender o uso da LD é como uma ferramenta que permite a criação de atividades educacionais interativas. Com o uso de recursos como o holofote, cortina, banco de imagens, instrumentos de desenho geométrico (esquadros, compasso, réguas, transferidor), é possível criar atividades diferenciadas, sem a necessidade de outros aplicativos além do próprio software da lousa, ainda que eles possam ser combinados. Caso se deseje que a atividade seja reutilizada, é possível salvá-la e utilizá-la em outras turmas ou em outras LD de mesmo modelo. Este tipo de uso dos recursos das LD é superior àqueles nos quais elas são usadas como tela de projeção ou como suporte para o uso de objetos de aprendizagem "prontos". Contudo, ainda não garante, por si só, a exploração de toda a potencialidade das LD. O fato de criar atividades na LD não assegura que os seus recursos de interação e interatividade sejam explorados. Esta exploração depende exclusivamente das formas de utilização que o professor faça das TD.

A criação de atividades diferenciadas em sala de aula é uma prática comum entre professores comprometidos com a aprendizagem dos seus alunos e, caso eles utilizem os recursos presentes nas LD, podem incrementar ainda mais esta prática. Este tipo de uso, contudo, exige do professor tempo e conhecimento (pedagógico e técnico) para o preparo adequado de atividades diferenciadas e criativas dominando, neste caso, tanto os OA quanto as LD.

Procurando relacionar numa única atividade as discussões sobre o uso da LD e dos OA, foi utilizada a carga horária da disciplina Tecnologias no Ensino de Matemática relativa às APCC para desenvolver ações práticas relacionadas ao uso destas TD em atividades pedagógicas de Matemática. Durante as aulas procurouse discutir com os alunos as dificuldades do uso das TD, suas particularidades, a necessidade de planejamento detalhado e de usar recursos tecnológicos que efetivamente agreguem novas possibilidades às atividades educacionais. Na etapa final da disciplina os alunos são instigados a criar suas próprias atividades, com base no que foi discutido e estudado anteriormente. 


\section{A prática perpassando a disciplina}

Como trabalho final da disciplina é pedido que cada aluno construa uma atividade com um conteúdo de Matemática no formato de OA. Os alunos podem escolher o assunto a ser trabalhado, seu grau de profundidade e que recursos utilizarão. A intenção é que eles desenvolvam atividades que utilizem $\mathrm{OA}$ agregados à LD que serão, posteriormente, disponibilizados na web, pela página do professor $^{8}$, para a comunidade interessada. Os alunos são incentivados a criar algo inédito, mas não é impedido que usem OA já desenvolvidos, desde que os complementem com outras atividades. Eles também podem utilizar sites, softwares, apresentações em PowerPoint, Word, softwares livres ou outros recursos, para trabalhar os assuntos escolhidos. Na entrega das atividades cada aluno apresenta sua proposta para a turma, que analisa, em conjunto, os objetos desenvolvidos. Acredita-se que

Este trabalho prático de formação de professores para o uso das TIC pode contribuir para formar novas gerações de professores que não sejam considerados imigrantes digitais. Uma formação diferenciada certamente colaborará para que se tenham professores com novos perfis e que saibam atuar de forma inovadora, usando não apenas as TIC, mas também outros recursos pedagógicos e soluções educacionais que os auxiliem a formar novas gerações, já imersas no mundo digital (KALINKE e MOCROSKY, 2014, p. 82).

O presente trabalho busca aprofundar esta análise e observar eventuais resultados obtidos pela repetição e aperfeiçoamento das estratégias adotadas ao longo dos oito semestres letivos de observações e levantamento de dados. Durante a oferta da disciplina, apenas o segundo semestre letivo de 2012 não foi trabalhado pelo mesmo professor. A figura 1 mostra a quantidade dos alunos matriculados nas turmas ao longo deste período. 
Figura 1 - Quantidade de alunos por semestre matriculados na disciplina Tecnologias no Ensino da Matemática

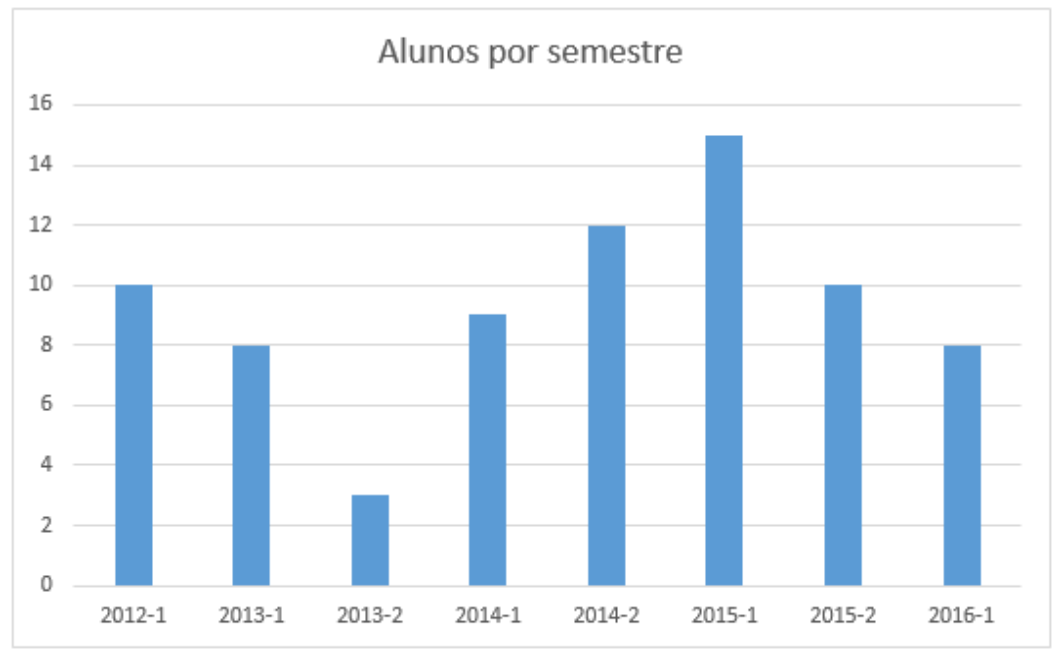

(Fonte: elaborado pelos autores)

Dos dados apresentados constata-se que foram desenvolvidos setenta e cinco trabalhos, que se propõe a criar ou utilizar objetos de aprendizagem nas lousas digitais. Destes, apenas quatro utilizaram OA já existentes, que foram complementados com exercícios, planos de aula e explicações teóricas sobre o assunto tratado. Os outros setenta e um objetos foram desenvolvidos pelos próprios alunos sobre diversos assuntos presentes nos currículos escolares de Matemática. A figura 2 relaciona os assuntos abordados nos trabalhos apresentados.

Figura 2 - Assuntos matemáticos abordados nos trabalhos da disciplina Tecnologias no Ensino de Matemática

\section{Assuntos abordados nos Objetos de Aprendizagem}

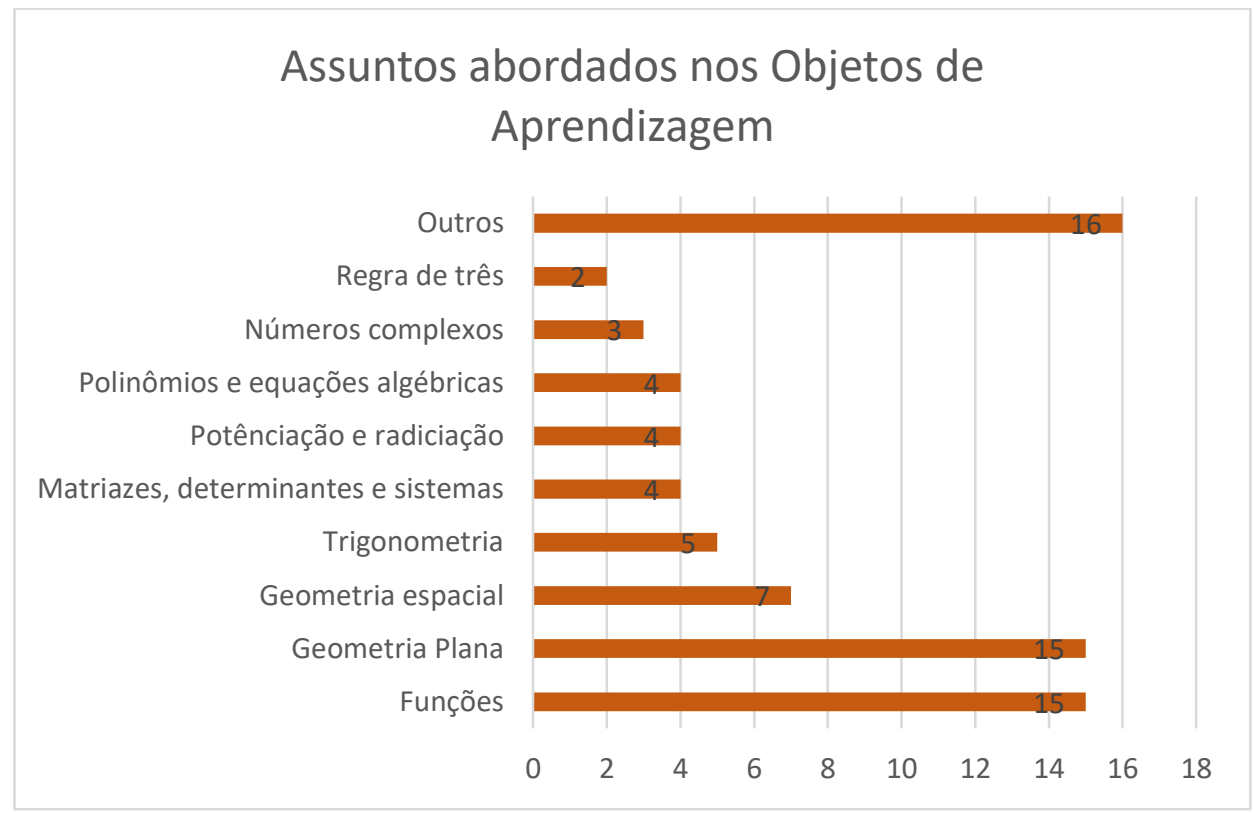

(Fonte: elaborado pelos autores) 
Percebe-se uma forte concentração de objetos desenvolvidos sobre os assuntos de funções, geometrias plana e espacial e trigonometria. Houve trabalhos com outros assuntos, em menor quantidade, tais como potenciação e radiciação e regra de três, por exemplo. Na categoria "outros" estão agrupados objetos que tratam de assuntos como sistemas de unidades, lógica matemática, estatística, matemática financeira, porcentagem, números inteiros e razão áurea, entre outros.

Boa parte do conteúdo matemático presente nos currículos dos ensinos fundamental e médio foi explorada pelos alunos. Dos trabalhos desenvolvidos, vinte e oito deles, o que corresponde a aproximadamente $37 \%$, são relativos ao ensino fundamental e quarenta a sete abordam assuntos do ensino médio, o que corresponde a um percentual arredondado de 63\%. Isto pode dar indícios de que os futuros professores apresentam uma predileção por conteúdos matemáticos considerados, por eles, mais difíceis de serem trabalhados. Os conteúdos de ensino fundamental são entendidos como mais básicos e simples.

Uma possível justificativa para esta percepção, que análises mais aprofundadas indicam como equivocada, pode residir no fato de que a disciplina em tela é trabalhada no terceiro período do curso. Neste momento da sua caminhada acadêmica os futuros professores ainda não tiveram contato com disciplinas que thes podem permitir entender a complexidade do trabalho com os conteúdos fundamentais da Matemática junto aos alunos do ensino fundamental. Eles ainda apresentam a visão de que a Matemática está relacionada ao trabalho com funções, logaritmos, números complexos, e outros assuntos similares. A valorização dos capítulos iniciais da Matemática, nos quais se trabalham conteúdos como potenciação e radiciação, operações numéricas, raciocínio lógico e outros, pode ainda não estar clara para os acadêmicos no terceiro período do curso. Outra possível explicação pode ser encontrada na visão corrente, e muitas vezes equivocada, de que a Matemática do ensino médio é mais difícil, e por isso merece ser trabalhada com novas tecnologias, enquanto a Matemática do ensino fundamental é mais fácil e, portanto, não precisa de apoio de novas estratégias e metodologias. De qualquer forma, este aspecto precisa ser melhor explorado em trabalhos futuros, que levem a uma melhor compreensão deste fenômeno.

\section{Algumas considerações e resultados}

Como aspecto relevante do trabalho em pauta evidencia-se o domínio da lousa digital, ou seja, de uma nova TD, pelos futuros professores. Merece destaque, contudo, para além do conhecimento sobre as funcionalidades destas lousas, que os trabalhos desenvolvidos indicam que os alunos da licenciatura perceberam que uma tecnologia possui potencialidades específicas que podem contribuir de forma significativa na criação de novas metodologias para o ensino da Matemática. Entre os trabalhos, a maioria absoluta foi desenvolvida de modo a explorar as lousas digitais em seu aspecto mais significativo quando da sua utilização em atividades educacionais. Entre as três possibilidades: apresentação os trabalhos estiveram centrados na criação de objetos de aprendizagem que, 
quando casados às lousas digitais, permitem a exploração das suas ferramentas e potencialidades. Assim, gerou-se, além dos conhecimentos técnicos necessários para o uso da LD, os conhecimentos pedagógicos que discutem de que forma as TD podem contribuir como diferenciais nas atividades de ensino de Matemática.

Para exemplificar o que os futuros professores desenvolveram pode-se observar os trabalhos a seguir, que tratam respectivamente de trigonometria, funções e geometria, escolhidos por estarem entre os assuntos mais presentes nos objetos criados. Estão selecionados, entre os objetos que abordam estes conteúdos matemáticos, alguns que foram desenvolvidos com diferentes aplicativos, sendo apresentados objetos criados a partir do GeoGebra, Excel e Power Point, destacando que o terceiro exemplo engloba dois destes aplicativos.

O primeiro objeto aqui apresentado aborda a trigonometria, foi desenvolvido no GeoGebra e permite acompanhar a criação de gráficos das funções trigonométricas a partir do valor dos seus respectivos arcos na circunferência trigonométrica, tal como ilustrado na figura 3.

Figura 3 - Tela de objeto de aprendizagem sobre gráficos de funções trigonométricas

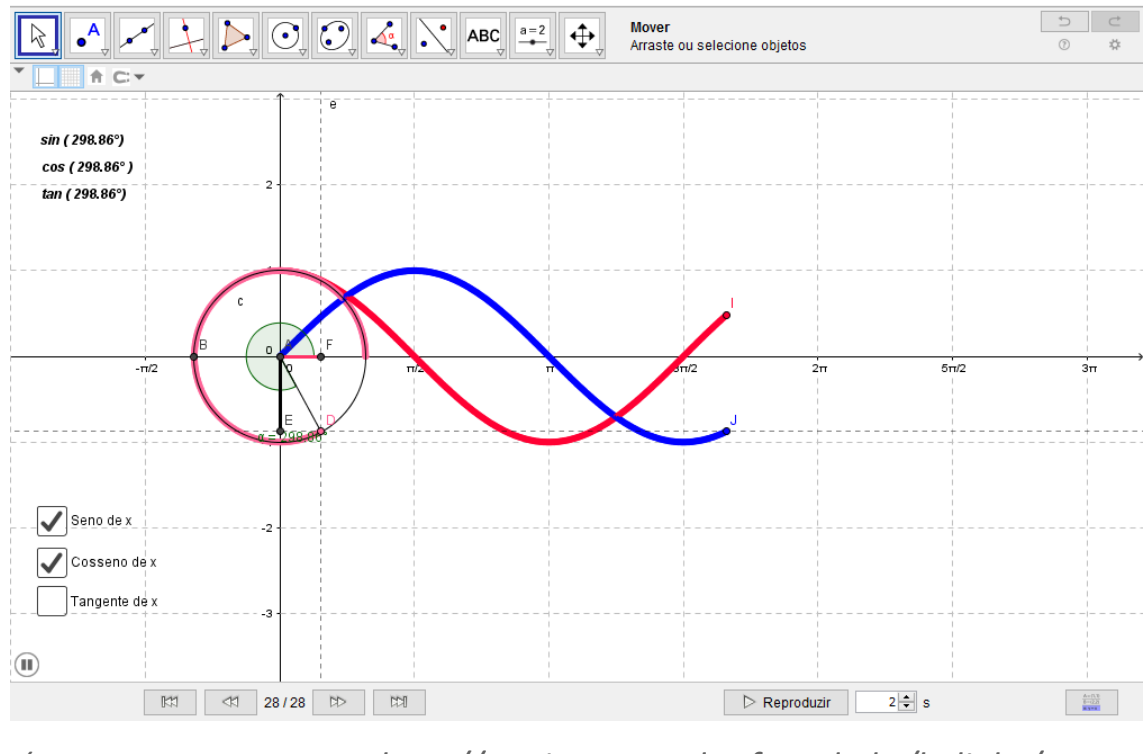

(Fonte: $\quad$ http://paginapessoal.utfpr.edu.br/kalinke/novastecnologias/trabalhos-desenvolvidos-por-alunos/tecnologias-no-ensino-damatematica/oa-1-2014/Lorena.zip)

O uso deste tipo de objeto na LD possibilita a articulação dos recursos do GeoGebra, como a animação de um ponto, com os da LD e com a possibilidade de controlar esta animação na própria tela de projeção, seja com a caneta específica ou com os dedos, dependendo do modelo de LD utilizado. Aliam-se os recursos de visualização, simulação, interação, interatividade e movimento, buscando a compreensão de conceitos matemáticos que, nos materiais didáticos convencionais, são apresentados de forma estática e isolada. Percebe-se, assim, uma exploração de recurso tecnológicos que vai além do que se consegue com os materiais impressos, explorando as TD de forma a que elas contribuam na compreensão de conceitos matemáticos. estatística. $\mathrm{O}$ objeto foi totalmente desenvolvido em Excel e explorou recursos de 
apresentação que não são comumente utilizados neste aplicativo. Foi utilizada no Excel uma sequência de telas interligadas que usavam os valores digitados ou calculados nas telas anteriores, simulando um jogo no qual o usuário precisa tomar decisões gerenciais baseadas em informações dadas a partir de gráficos estatísticos. A tela inicial está apresentada na figura 4.

Figura 4 - Tela de objeto de aprendizagem desenvolvido no Excel

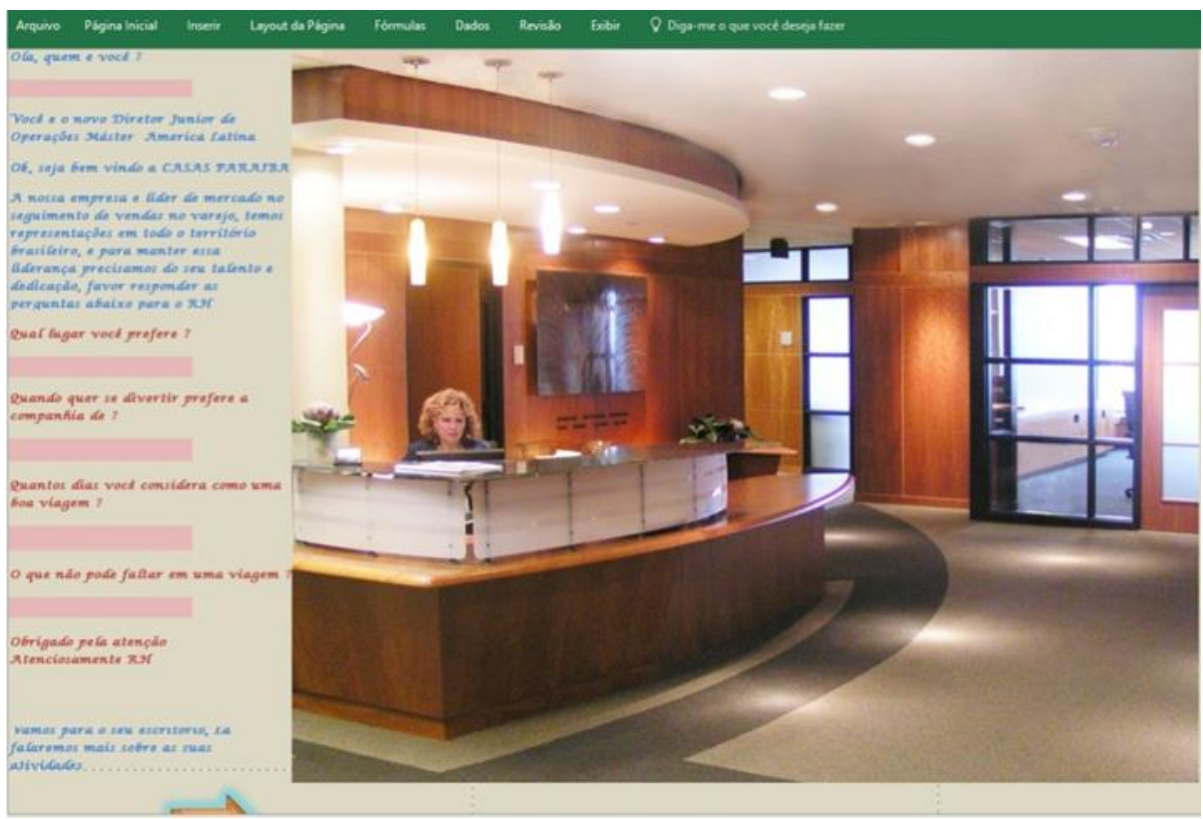

(Fonte: http://paginapessoal.utfpr.edu.br/kalinke/novas-tecnologias/trabalhosdesenvolvidos-por-alunos/oa2-2015/Fabiano.zip)

Este objeto, quando utilizado na LD permite o envolvimento dos alunos numa competição para ver quem toma as melhores decisões gerenciais. A interação, neste caso, fica fortemente incentivada e pode favorecer a construção de uma inteligência coletiva, tal como proposto por Lévy (1999). A LD ainda permite explorar, em paralelo, outros recursos que podem ser úteis durante as atividades, tais como a navegação em sites que contenham informações sobre mercados financeiros, outros aplicativos gráficos e calculadoras, por exemplo.

O terceiro exemplo trata de um jogo desenvolvido em Power Point que usava, em algumas telas específicas, outros aplicativos, tais como o GeoGebra. O objetivo do jogo, inspirado no clássico game Donkey Kong, é que o usuário realize algumas tarefas sobre os sólidos de revolução, para avançar e passar de fases.

Para ilustrar os tipos de tarefas exploradas, pode-se visualizar a figura 5, que apresenta uma malha de pontos que podem ser movimentados e cuja visualização do sólido gerado pela sua revolução aparece imediatamente ao lado. No caso apresentado, a intenção é que o usuário perceba que é possível gerar a representação de um cone partindo-se da rotação de um triângulo retângulo em torno de um dos seus catetos. 


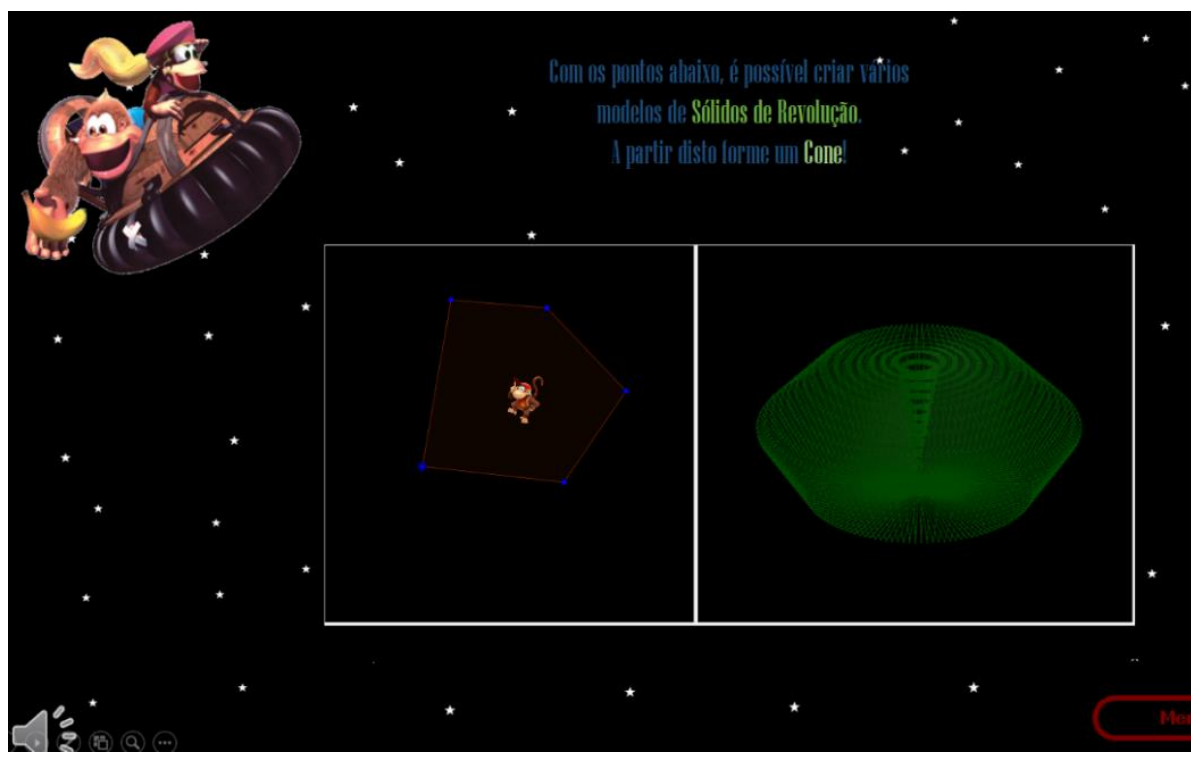

(Fonte: http://paginapessoal.utfpr.edu.br/kalinke/novas-tecnologias/trabalhosdesenvolvidos-por-alunos/oa2-2015/Tatiana.zip)

Um objeto como este possibilita aos usuários aspectos de visualização, interatividade e simulação. Quando utilizado na LD, tal objeto contribui para que haja maior interação com os demais colegas, o que pode criar um ambiente favorável tanto à constituição de uma inteligência coletiva quanto um coletivo pensante que dificilmente seriam conseguidos sem o uso combinado destes recursos.

No trabalho realizado com futuros professores compreendemos que ao utilizar as LD para explorar os objetos de aprendizagem os alunos se apropriam de possibilidades tecnológicas que, somadas, levam a um resultado no qual a soma final é maior do que a soma das partes. A promoção do encontro dos OA com as LD explora os diferenciais dos OA, tais como a possibilidade de interatividade, por exemplo. O uso de OA em outras mídias, tais como os computadores ou tablets, também permite esta exploração. Os diferenciais da LD, por sua vez, entre os quais estão as suas ferramentas de manipulação e interação, podem ser explorados em outras atividades que não usem OA. A junção dos dois, contudo, permite que a interatividade entre o usuário e o objeto em questão seja complementada pela interação entre os diversos usuários que podem contribuir com a atividade, numa ação colaborativa de construção de conhecimento. Os objetos apresentados dão mostras de que este aspecto foi compreendido e assimilado pelos alunos da disciplina.

O uso conjunto e articulado de diversos recursos tecnológicos permite algumas explorações e inserções interessantes nas atividades de Matemática realizadas em sala de aula. Entre elas se pode destacar a inclusão da linguagem digital interativa em atividades matemáticas. Esta linguagem faz parte da vida social dos alunos com uma presença significativa, uma vez que é utilizada nas televisões, celulares, tablets e computadores, por exemplo, que são dispositivos aos quais as novas gerações têm acesso e cujo uso dominam quase naturalmente, conforme exposto em Nakashima e Amaral (2006). Esta linguagem, contudo, ainda 
não está presente nas salas de aula, particularmente nas aulas de Matemática. 0 uso da LD e dos OA pode contribuir para esta inclusão.

As características da LD, especialmente pelas suas dimensões, permitem explorar de forma inovadora atividades interativas que podem levar à criação de novos coletivos, tal como defendido por Lévy (1999). A reorganização do pensamento, como defendida por Tikhomirov (1981) e a exploração dos coletivos seres-humanos-com-mídias..., tal como proposto em Borba e Vilarreal (2005) também podem se fazer presentes de forma diferenciada, uma vez que novas possibilidades são apresentadas com o potencial investigativo que a exploração enseja.

Espera-se que os futuros professores possam colocar em prática, nas suas rotinas profissionais quando docentes, as ideias apresentadas, discutidas e desenvolvidas na disciplina que participou da sua formação inicial. Deseja-se, assim, que a proposta realizada seja inspiradora de práticas pedagógicas que possam, efetivamente, inserir as TD em aulas de Matemática de forma a contribuir na construção do conhecimento matemático de forma inovadora e diferenciada. 


\title{
Digital technologies used in the formation of future mathematics teachers
}

\begin{abstract}
The models of atual mathematics teacher's training courses search for linking future teachers and their professional practice during their graduation. This requires new approaches from the teachers, searching, during the graduation disciplines, for the students to learn new possibilities and practices that should be used by students once they are graduated. The research presents a discussion about this graduation model and how its approximation was developed in a particular discipline, the one which it's content is related to the insertion of technologic recourses on the ways of teaching mathematics. The discipline's ways of work, the theoretical background adopted and some results of the developed work, analyzed by the new practices in teacher's formation, are presented. Between the results, it could be understood that the use of digital technologies in different ways can encourage, in future teachers, new postures and possibilities. Furthermore, the articulated use of technological resources turned possible the inclusion of a digital and interactive new language in mathematics activities .
\end{abstract}

KEYWORDS: Mathematics Education. Technologies. Learning objects. 


\section{REFERÊNCIAS}

BORBA, M. C.; VILLARREAL, M. E. Humans - with - Media and the Reorganization of Mathematical Thinking: Information and Communication Technologies, Modeling, Experimentation and Visualization. New York: Springer, 2005.

DEROSSI, B. Objetos de aprendizagem e lousa digital no trabalho com álgebra: as estratégias dos alunos na utilização desses recursos. Dissertação de mestrado: UFPR - Curitiba, 2015.

GALLO, P., PINTO, M. G. Professor, esse é o Objeto Virtual de Aprendizagem. Revista Tecnologias na Educação, ano 2, n.1, Jul. 2010.

JANEGITZ, L. E. Indícios da existência do coletivo seres-humanos-com-lousadigital e a produção de conhecimento matemático. Dissertação de mestrado: UFPR - Curitiba, 2014.

KALINKE, M. A.; JANEGITZ, L. E. A Lousa Digital e a Formação de Professores de Matemática. In: Anais do IV Simpósio Nacional de Ensino de Ciência e Tecnologia, 2014.

KALINKE, M. A.; MOCROSKY, L. Objetos de aprendizagem e lousas digitais: uma experiência no curso de Licenciatura em Matemática. In: Tecnologias digitais em educação: perspectivas teóricas e metodológicas sobre formação e prática docente. Organização de Adriana Richit. Editora CRV: Curitiba, p. 57-86, 2014.

LÉVY, P. As tecnologias da Inteligência: o futuro do pensamento na era da informática. Rio de Janeiro: Ed. 34, 1993.

Cibercultura. São Paulo: Ed. 34, 1999.

MOCROSKY, L.F; KALINKE, M.A; ESTEPHAN, V.M. A prática como componente curricular na formação inicial do professor de Matemática: em busca de compreensões. In:Formação do professor de Matemática: reflexões e propostas. Organização Helena Noronha Cury; Carlos Roberto Vianna. Editora IPR: Santa Cruz do Sul, p. 333-362, 2012.

Nakashima, R. H. R.; Amaral, S. F. A linguagem audiovisual da lousa digital interativa no contexto educacional. Educação Temática Digital, Campinas, v.8, n.1, p. 33-48, dez. 2006. 
RIBEIRO, M. S. N. A lousa digital no fundamental I: formas de utilização no ensino da Matemática. Dissertação de mestrado: UFPR - Curitiba, 2015.

TIKHOMIROV, O. K. The psychological Consequences of Computarization. In Wertsch, J. V. (Ed.). The Concept of Activity in Soviet Psychology. New York: M. E. Sharpe Inc., p. 256- 278, 1981.

Recebido: 2016-08-22

Aprovado: 2017-07-27

DOI: $10.3895 /$ rbect.v10n2.4546

Como citar: KALINKE, M. A.; MOCROSKY, L. F.; PANOSSIAN, M. L.; BANIN, E. S. Tecnologias digitais na formação e prática dos futuros professores de Matemática. Revista Brasileira de Ensino de Ciência e Tecnologia, v. 10, n. 2, 2017. Disponível em: <https://revistas.utfpr.edu.br/rbect/article/view/4546>. Acesso em: xxx.

Correspondência:

Direito autoral: Este artigo está licenciado sob os termos da Licença Creative Commons-Atribuição 4.0 Internacional.

\section{(c) (1)}

